\begin{abstract}
ALKOR-Berichte
Open-Water Test of the LIGHTHOUSE Situational Awareness System
\end{abstract}

Cruise No. AL555

\author{
28.4.21- 11.5.21 \\ Kiel (Germany) - Kiel (Germany) \\ LIGHTHOUSE-DM
}

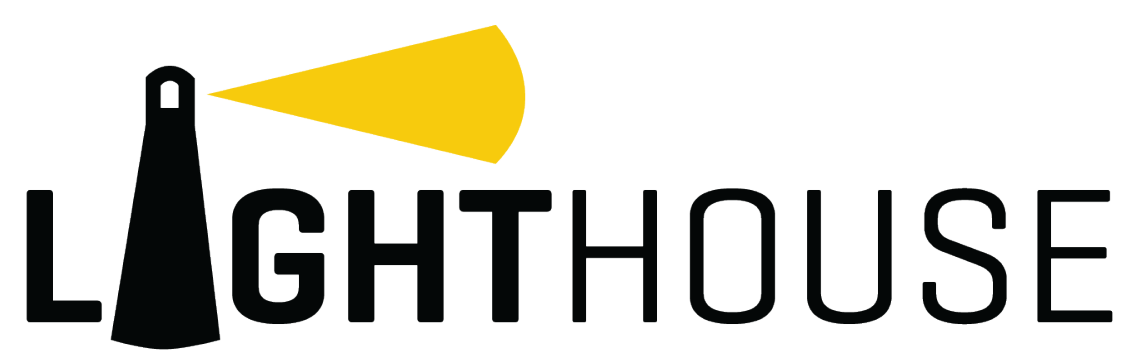

T. Kwasnitschka

Chief Scientist

GEOMAR Helmholtz Centre for Ocean Research Kiel 


\section{Table of Contents}

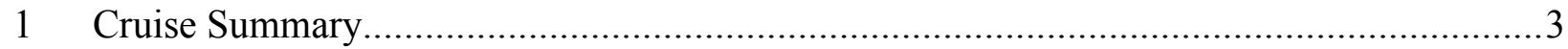

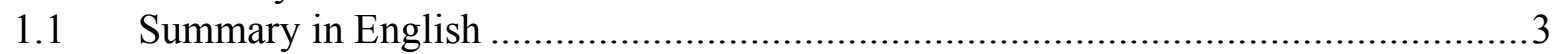

1.2 Zusammenfassung .................................................................................... 3

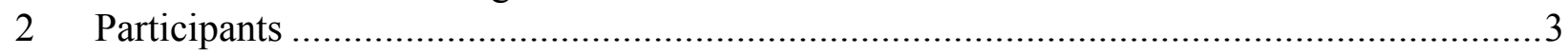

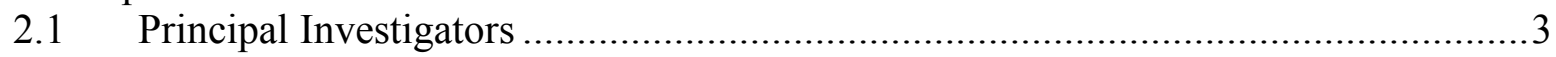

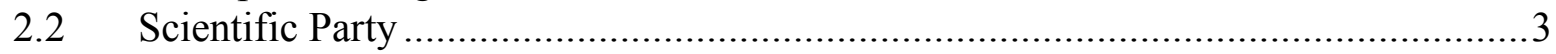

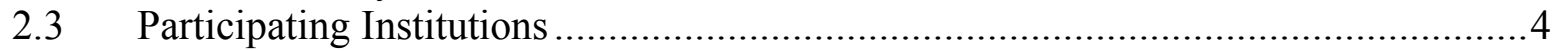

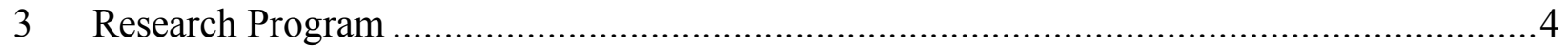

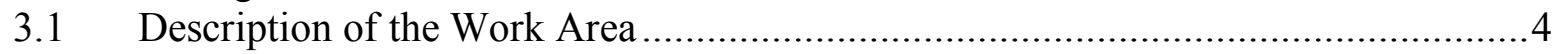

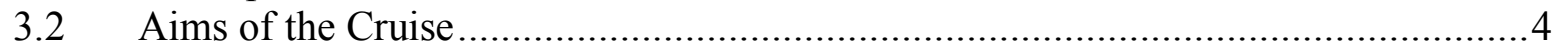

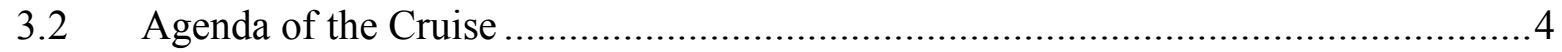

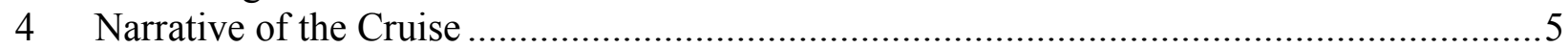

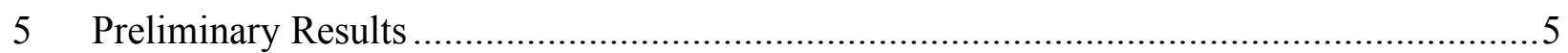

$7 \quad$ Station List AL555

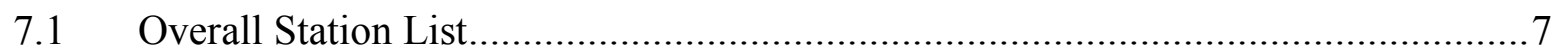

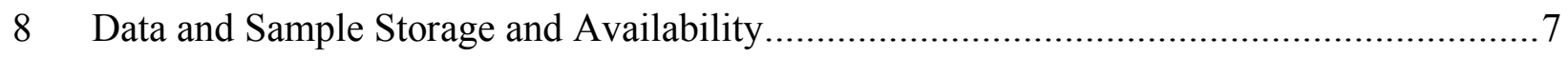

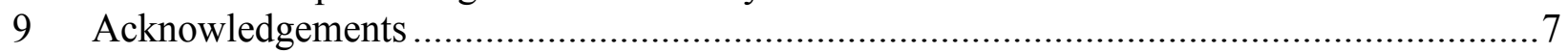

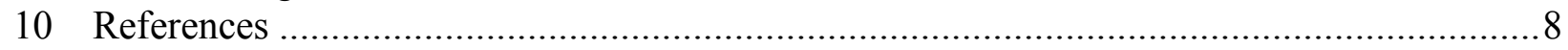

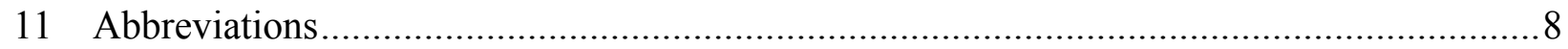

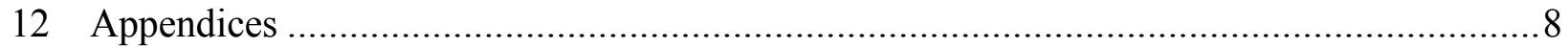

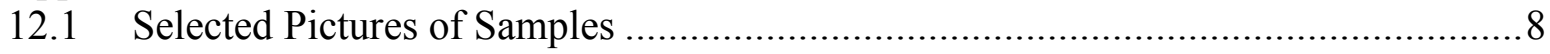

12.2 Selected Pictures of Shipboard Operations..................................................... 


\subsection{Summary in English}

The objective of this cruise was to establish the first order functionality of the LIGHTHOUSE system in terms of mechanics, ROV operations, electrical components and data link. This is a highly integrated suite of optical and acoustic sensors to create a real time $360^{\circ}$ scan of an underwater environment, in order to enhance the situational awareness of pilots and mission specialists. The tests were to be conducted in the clear, deep waters of the Norwegian Sognefjord. Due to severe technical malfunctions that became only apparent during mobilization in the port of Kiel, the vessel stayed moored to the east shore and west shore quays in Kiel Harbor, except for an excursion off Boknis Eck in the Eckernförde Bight. Despite these restrictions in locality, the majority of the work programme was carried out with great success.

\section{$1.2 \quad$ Zusammenfassung}

Ziel der Fahrt war die grundsätzliche Demonstration der Funktionalität des LIGHTHOUSE Systems in Bezug auf Mechanik, ROV-Operationen, Elektrik und Datenverbindung. Dies ist ein System hochgradig integrierter optischer und akustischer Sensoren, welche in Echtzeit einen $360^{\circ}$-Scan der Umgebung rings um einen Tauchroboter liefern und so für Piloten und Wissenschaftler ein erhöhtes Situationsbewusstsein schaffen. Die Feldversuche sollten ursprünglich in den klaren, tiefen Gewässern des norwegischen Sognefjords durchgeführt werden. Aufgrund schwerwiegender technischer Probleme, welche sich erst bei der Mobilisierung an Bord ergaben, verblieb das Schiff jedoch am Kieler Ost- bzw. Westuferkai für die Dauer der Fahrtzeit, abgesehen von einer Tagesfahrt vor Boknis Eck, Eckernförder Bucht. Ungeachtet dieser Einschränkungen im Fahrtziel wurde der überwiegende Teil des Arbeitsprogrammes mit großem Erfolg absolviert.

\section{Participants}

2.1 Principal Investigator

\begin{tabular}{ll}
\hline Name & Institution \\
\hline Kwasnitschka, Tom, Dr. & GEOMAR \\
\hline
\end{tabular}

\section{2}

Scientific Party

\begin{tabular}{lll}
\hline Name & Discipline & Institution \\
\hline Kwasnitschka, Tom, Dr. & Principal Investigator / Chief Scientist & GEOMAR \\
Rohleder, Marco & Chief Engineer & GEOMAR \\
Jahns, Stefan & Software Engineer & GEOMAR \\
Pieper, Martin & Chief Engineer, ROV & GEOMAR \\
Cuno, Patrick & Software Engineer & GEOMAR \\
Bodendorfer, Matthias & Mechanical Engineer & GEOMAR \\
Huusmann, Hannes & Media Engineer & GEOMAR \\
\hline
\end{tabular}




\subsection{Participating Institutions}

GEOMAR Helmholtz-Zentrum für Ozeanforschung Kiel

\section{$3 \quad$ Research Program}

\subsection{Description of the Work Area}

The Sognefjord is the longest and one of the deepest of the Norwegian fjords. As such, it provides extremely sheltered, yet quickly accessible deep-water environments for the efficient testing of marine technology in development. Boknis Eck provides depths of up to $28 \mathrm{~m}$, which is the closest area below $20 \mathrm{~m}$ in the German waters off Kiel harbor.

\subsection{Aims of the Cruise}

The cruise was planned as a focused round of sea trials for the ROV-based situational awareness and mapping system LIGHTHOUSE. It is being developed under a federal venture capital grant from the Helmholtz Association through its Helmholtz Validation Fund (HVF). The goal of Project 0068, „LIGHTHOUSE - System zur Echtzeit-Visualisierung von Unterwasserumgebungen für Tauchroboter" is to overcome limitations of most remotely operated vehicles (ROVs) which sensors are focused to one lateral sector, leaving the other sectors uncovered. This results in loss of intelligence for mission specialists and reduced situational awareness for the pilots. LIGHTHOUSE seeks to change this. The LIGHTHOUSE system generally consists of a suite of cameras, optical and acoustic seafloor shape acquisition devices, software to visualize their products as well as telemetry and hardware to accommodate the sensors on a remotely operated vehicle.

\subsection{Agenda of the Cruise}

We had originally applied to take ROV PHOCA aboard ALKOR to the Sognefjord in central Norway. This water body is comparatively close to Kiel, requiring no shipping to an external port, water depths beyond $1200 \mathrm{~m}$ but extremely calm since sheltered weather conditions, the type of which is necessary for controlled, experimental deployments of novel equipment. We had planned to conduct four dives one day each, covering a cascade of functional and operational tests as well as calibration runs and collection of sample data. There were no plans to collect or publish any data of specific scientific relevance, though. The important feature of the working area is hard seafloor substrate for surface scans (i.e. rock walls) and the water depth beyond $1000 \mathrm{~m}$, which had been identified as an operational benchmark in the project. The cruise was planned as the first of a series of three rather identical cruises to this working area, each as an increment over the achievements of the former, with time in the workshop in between. Unfortunately, as laid out in the narrative of this report, the development of events led us not to persue the cruise to Norway, but to undertake the essential work in the harbor of Kiel and directly offshore Eckernförde. 


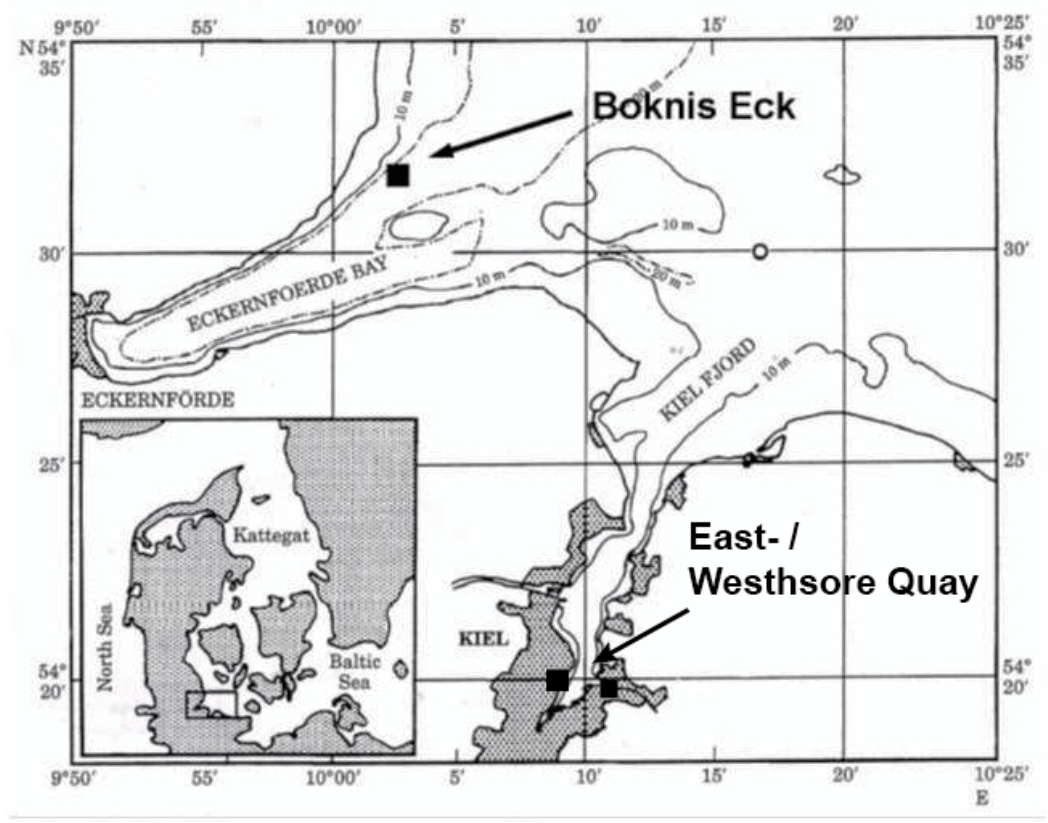

Fig. 3.1 Positions of R/V ALKOR Cruise AL555. Bathymetry from www.bokniseck.de. Black rectangles mark the two dock sites in Kiel Harbor and the position of the test dive near Boknis Eck.

\section{$4 \quad$ Narrative of the Cruise}

\section{Wednesday, 28-04-2021:}

The ROV was loaded onto the vessel shortly after 9 am, followed by the scientific gear. At the same time, the science party arrived from COVID-quarantine at home or in a nearby hotel via shuttle transfer. Following the hygiene plan at the time, the science party stayed on the vessel without direct shoreside contact in order to facilitate a safe multi-day cruise. Furthermore, we operated under a reduced-staff, single berth cabin scheme of only seven scientists and engineers next to the crew. While the ROV team spent the rest of the day for setup, the science party set up the LIGHTHOUSE system in the hangar and the topside components in the dry lab for final dry tests.

\section{Thursday, 29-04-2021:}

The ROV team finished setup with a wet buoyancy harbor test of the ROV with LIGHTHOUSE modifications, but without the sensors installed, in the afternoon. In the meantime, it became apparent that there were severe functionality issues concerning a novel, externally sourced underwater laser sensor system which is an integral part of LIGHTHOUSE and the cruise aims. Details cannot be disclosed at this point for reasons of IP security. These faults were so severe that this system would not be operational at all during the upcoming cruise. The manufacturer was contacted, accepted responsibility, and remote support through a dedicated LTE line was initiated immediately.

Friday, 30-04-2021 - Saturday 01-05-2021:

Both days had to be dedicated to fault checking of the laser system. This work required a stable internet connection (only to be guaranteed in German waters), a steady ship and much of 
the central LIGHTHOUSE components open on the bench. Thus, other preparatory work on the system including a wet harbor test of the sensor suite had to be postponed.

\section{Sunday, 02-05-2021:}

A first harbor test was conducted with the full LIGHTHOUSE System. The mechanical, the electrical and data link integration to the ROV was verified. Due to the limited deck space, critical components of the system need to be moved by crane from the hangar to the stern, since the ROV control container blocks all but a narrow alley midship to cross the deck. Functioning of critical LIGHTHOUSE 3D acquisition devices was finally verified on deck and in the water.

At the same time, though everything was finally ready to depart, in light of unfavorable weather conditions for transit to Norway, and due to the amount of cruise time lost, it was decided not to sail to Norway but to invest the transit time into further ROV harbor and shallow offshore tests in German waters, to maximize the amount of time spent with the system wet and in working order. Consequently, the quarantine was lifted and the science party was allowed to return home after daily work. As a technical test cruise, the focus of the project was in the verification and practical deployment of the LIGHTHOUSE equipment on an actual ROV in the water - not in the visiting and sampling of a particular spot, as in the case of scientific cruises. It may be noted that GEOMAR has no extensive test tank facilities for such work, that LIGHTHOUSE does not work in confined tanks, such that ALKOR-based ROV deployments, even in the Kiel Fjord, are an economical means to test this technology.

\section{Monday 3-5-21 - Friday 7-5-21:}

The following days were used for extensive functional tests including long duration stress tests of the LIGHTHOUSE system. The poor water quality with algal blooms partially precluded the collection of optical sample data, but all the general tasks such as system stability, monitoring of power consumption, maneuverability of the ROV in light of LIGHTHOUSE enhancements, and topside practical handling of all LIGHTOUSE components (i.e., the major milestones that had been set for the cruise) could be achieved. In the meantime, the vessel was moved from its east shore quay to the west shore quay, where we had favorable structures (the quay pillars) for underwater imaging as well as sheltered ROV deployment conditions.

\section{Saturday 8-5-21:}

The vessel departed the west shore shortly after 8am heading for Boknis Eck off Eckernförde. Here, in water depths of about $20 \mathrm{~m}$ with rocky substrate, a calibration target containing a tetrahedral metal frame of $3 \mathrm{~m}$ corner length was moored $5 \mathrm{~m}$ above the seafloor suspended from a buoy. Shortly after, the ROV was deployed and calibration maneuvers were conducted around the mooring, imaging the structure with the various LIGHTHOUSE sensors. Such a maneuver is important to fine tune calibration and resolution of the sensors to a structure of known extent. Due to limited visibility impacted by algal bloom, the dive was concluded after two hours.

\section{Monday 9-5-21 - Tuesday 10-5-21:}

Due to the limited visibility conditions and the lack of visual reference outside the harbor, further offshore tests were judged not to yield an advantage over the harbor tests with very well known, structured objects. Thus, optical and acoustical sensor tests with the ROV in the harbor off the GEOMAR west shore building concluded the ship time, including collection of acoustic test data.

\section{Wednesday 11-5-21:}

Unloading of the scientific equipment and ROV shortly after 9 am concluded the cruise. 


\section{$5 \quad$ Preliminary Results}

The HVF program is based on the idea first to validate a concept and then to monetize it with external industrial partners. This means that not only there is a requirement on extra tight control and protection of the intellectual property involved and developed, but also, in case of commercial success, an interest much in excess of the original funds received is due as revenue to the HVF. Consequently, since the assessment of innovation and the claiming of patents has not yet been finalized, we were legally advised not provide details on the system, the arrangement of its external components, nor photographs. We thus regret that such details cannot be part of this report. We expect such details to be publicly available by the end of 2022 .

Altogether, we were able to verify the principal functioning of the system as intended, particularly with respect to the interaction with the ROV and the working of the central telemetry components.

\section{$6 \quad$ Station List AL555}

\subsection{Overall Station List}

\begin{tabular}{|c|c|c|c|c|c|c|c|c|}
\hline \multicolumn{2}{|c|}{ Station No. } & Date & Gear & $\begin{array}{c}\text { Tim } \\
\text { e }\end{array}$ & Latitude & Longitude & $\begin{array}{c}\text { Water } \\
\text { Depth }\end{array}$ & Remarks/Recovery \\
\hline AL555 & GEOMAR & $\mathbf{2 0 2 1}$ & & $\begin{array}{c}{[\mathbf{U T}} \\
\mathbf{C}]\end{array}$ & $\left.{ }^{\circ} \mathbf{N}\right]$ & {$\left[^{\circ} \mathbf{W}\right]$} & {$[\mathbf{m}]$} & na \\
\hline $2-1$ & 1 & 8.5 & $\begin{array}{c}\text { Mooring } \\
\text { deployment }\end{array}$ & $08: 07$ & $54^{\circ} 31,416^{\prime}$ & $010^{\circ} 01,526^{\prime}$ & 28 & na \\
\hline $3-1$ & 2 & 8.5. & $\begin{array}{c}\text { ROV } \\
\text { deployment }\end{array}$ & $08: 37$ & $54^{\circ} 31,390^{\prime}$ & $010^{\circ} 01,486^{\prime}$ & 28 & na \\
\hline $3-1$ & 3 & 8.5. & $\begin{array}{c}\text { ROV } \\
\text { recovery }\end{array}$ & $10: 53$ & $54^{\circ} 31,386^{\prime}$ & $010^{\circ} 01,462^{\prime}$ & 28 & na \\
\hline $4-1$ & 4 & 8.5. & $\begin{array}{c}\text { Mooring } \\
\text { recovery }\end{array}$ & $11: 48$ & $54^{\circ} 31,411^{\prime}$ & $010^{\circ} 01,538^{\prime}$ & 28 & 28 \\
\hline
\end{tabular}

\section{$7 \quad$ Data and Sample Storage and Availability}

Test data was merely collected to validate the functioning of the equipment, and for calibration of sensor orientation. There is no scientific value in the data gathered, and no curated release of this data is planned. It should also be noted that the absolute georeferencing was unavailable due to a fault in the processing chain of the navigational sensors.

Table 7.1 Overview of data availability

\begin{tabular}{|l|c|c|c|c|}
\hline Type & Database & Available & $\begin{array}{l}\text { Free } \\
\text { Access }\end{array}$ & Contact \\
\hline $\begin{array}{l}\text { 3D acoustic } \\
\text { imagery }\end{array}$ & Local & Dec. 22 & Dec. 22 & $\begin{array}{l}\text { tkwasnitschka@ } \\
\text { geomar.de }\end{array}$ \\
\hline
\end{tabular}

\section{Acknowledgements}

The project was funded through the HVF68 LIGHTHOUSE project, granted through the Helmholtz Validation Fund of the Helmholtz Association. 
9 References

None.

10 Abbreviations

ROV - Remotely Operated Vehicle

11 Appendices

11.1 Selected Pictures of Samples

None collected.

\subsection{Selected Pictures of Shipboard Operations}

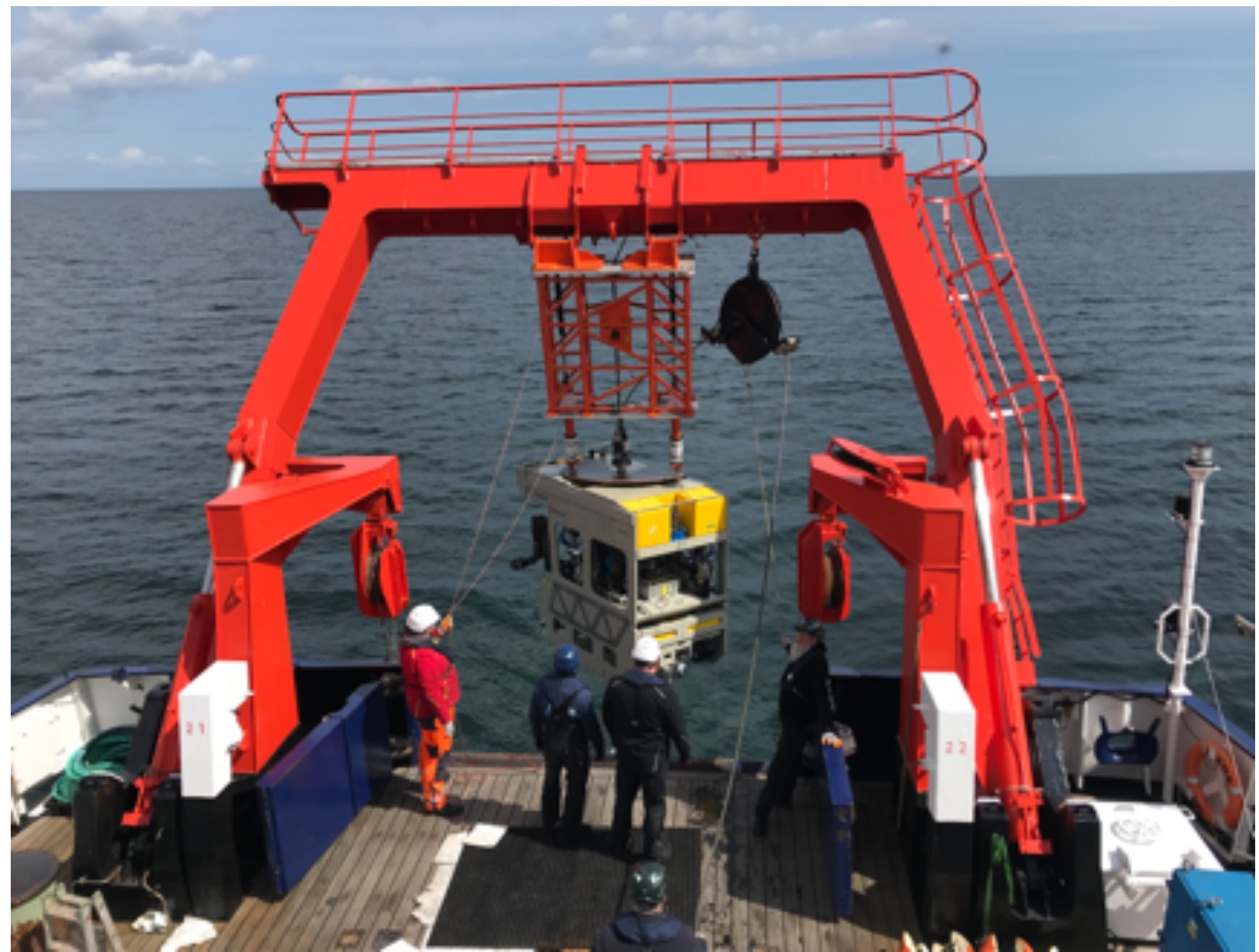

Fig. 12.1 ROV PHOCA with the LIGHTHOUSE modifications during the deployment off Boknis Eck on May 8th, 2021 